\title{
Impaired baroreflex function in mice overexpressing alpha-synuclein
}

\section{Sheila M. Fleming 1,2*, Maria C. Jordan ${ }^{3}$, Caitlin K. Mulligan ${ }^{4}$, Eliezer Masliah ${ }^{5}$, John G. Holden ${ }^{1}$, Ronald W. Millard ${ }^{6}$, Marie-Françoise Chesselet ${ }^{4,7}$ and Kenneth P. Roos ${ }^{3}$}

\author{
1 Department of Psychology, University of Cincinnati, Cincinnati, OH, USA \\ 2 Department of Neurology, University of Cincinnati, Cincinnati, OH, USA \\ ${ }^{3}$ Department of Physiology, David Geffen School of Medicine, University of California Los Angeles, Los Angeles, CA, USA \\ ${ }^{4}$ Department of Neurology, David Geffen School of Medicine, University of California Los Angeles, Los Angeles, CA, USA \\ ${ }^{5}$ Department of Neuroscience, University of California San Diego, San Diego, CA, USA \\ ${ }^{6}$ Departments of Pharmacology and Cell Biophysics, University of Cincinnati, Cincinnati, OH, USA \\ 7 Department of Neurobiology, David Geffen School of Medicine, University of California Los Angeles, Los Angeles, CA, USA
}

Edited by:

Santiago Perez-Lloret, Toulouse

University, France

\section{Reviewed by:}

Kevin Monahan, Penn State College

of Medicine, USA

Shyamal Mehta, Georgia Health

Sciences University, USA

*Correspondence:

Sheila M. Fleming, Departments of

Psychology and Neurology, University

of Cincinnati, PO Box 210376

Cincinnati, OH 45221-0376, USA

e-mail:fleminsa@ucmail.uc.edu
Cardiovascular autonomic dysfunction, such as orthostatic hypotension consequent to baroreflex failure and cardiac sympathetic denervation, is frequently observed in the synucleinopathy Parkinson's disease (PD). In the present study, the baroreceptor reflex was assessed in mice overexpressing human wildtype alpha-synuclein (Thy1-aSyn), a genetic mouse model of synucleinopathy. The beat-to-beat change in heart rate (HR), computed from R-R interval, in relation to blood pressure was measured in anesthetized and conscious mice equipped with arterial blood pressure telemetry transducers during transient bouts of hypertension and hypotension. Compared to wildtype, tachycardia following nitroprusside-induced hypotension was significantly reduced in Thy1-aSyn mice. Thy1-aSyn mice also showed an abnormal cardiovascular response (i.e., diminished tachycardia) to muscarinic blockade with atropine. We conclude that Thy1-aSyn mice have impaired basal and dynamic range of sympathetic and parasympathetic-mediated changes in HR and will be a useful model for long-term study of cardiovascular autonomic dysfunction associated with PD.

Keywords: Parkinson's disease, alpha-synuclein, orthostatic hypotension, baroreflex, mouse model

\section{INTRODUCTION}

Baroreflex failure is documented in patients with Parkinson's disease (PD) and is often considered as the root cause for observed orthostatic hypotension $(1,2)$. Recently, orthostatic hypotension, baroreflex failure, and sympathetic denervation have been reported to occur early in PD, before the onset of overt motor symptoms, making cardiovascular autonomic dysfunction a potential PD biomarker for the development of diseasemodifying treatments (3-7). To date few studies have reported cardiovascular autonomic dysfunction in PD mouse models and the pathologic mechanisms underlying PD-related cardiovascular autonomic dysfunction remain to be elucidated (8-11).

In PD, Lewy bodies containing alpha-synuclein have been observed in peripheral sympathetic areas including stellate ganglia and the cardiac plexus, as well as in central brainstem areas important for regulation of blood pressure and peripheral vascular resistance and compliance (12-14). Patients with a form of familial PD associated with alpha-synuclein locus triplication show impaired baroreflex-cardiovagal gain and reduced cardiac sympathetic innervation suggesting a potentially important role for alpha-synuclein in the pathogenesis of autonomic dysfunction in PD (15). Therefore, in this study we sought to characterize baroreceptor function in transgenic mice overexpressing alpha-synuclein under the Thyl promoter [Thyl-aSyn; (16)]. These mice have increased alpha-synuclein levels in central and peripheral neurons and develop proteinase K-resistant alpha-synuclein aggregates in multiple brain regions, including the substantia nigra, locus coeruleus, and olfactory bulb (16-18). Thy1-aSyn mice display both motor and non-motor impairments including gastrointestinal and olfactory dysfunction reminiscent to that observed in PD (18-22). In addition, by 14 months of age, these mice have a significant decrease in striatal dopamine and L-DOPA responsive behavioral deficits (23). In the present study, we assessed morphometry parameters, baroreceptor reflex, and left ventricular contractility in Thy1-aSyn and wildtype (WT) mice.

\section{MATERIALS AND METHODS \\ ANIMALS}

Animal care was conducted in accordance with the United States Public Health Service Guide for the Care and Use of Laboratory Animals, and procedures were pre-approved by the Institutional Animal Care and Use Committee at the University of California Los Angeles. Transgenic mice overexpressing human alphasynuclein under the Thyl promoter (Thy1-aSyn) were crossed into a hybrid C57BL/6-DBA/2 background (16). Animals were maintained on the hybrid C57BL/6-DBA/2 background by breeding mutant females with male mice on the hybrid background (18, $24,25)$. Littermates were never inbred. The genotype of all ThylaSyn and WT mice was confirmed with polymerase chain reaction (PCR) amplification analysis of DNA from tail tips at birth and 
confirmed at the end of the experiment. All mice were individually housed with free access to water and standard rodent chow.

Male mice from a total of 21 litters were used in this study. Litter sizes ranged from 2 to 11 mice. Separate cohorts of mice were used in the hemodynamic-baroreflex protocol (Thyl-aSyn $=9$, $\mathrm{WT}=9)$ and for the heart rate (HR) and contractility dobutamine challenge protocol (Thyl-aSyn $=7 ; \mathrm{WT}=7$ ) at 9-12 months of age. An additional separate cohort of mice (Thy1-aSyn $=3-4$, $\mathrm{WT}=3-5$ ) was implanted with arterial transducers and tested at 3-5 months of age. A younger cohort in the arterial transducer experiment was included because the survival rate in older animals was too low.

\section{MORPHOMETRY}

Following hemodynamic assessment surgeries Thyl-aSyn and WT mice were euthanized and heart, lung, and liver weights were measured and tibia length determined.

\section{HEMODYNAMIC ASSESSMENT}

Hemodynamic assessment was performed as previously described (26-29). Briefly, in Thyl-aSyn and WT mice anesthetized with ketamine, xylazine, and buprenorphine, both femoral arteries were catheterized with flame-stretched PE-50 tubing (30). One catheter was interfaced to a pressure transducer connected to the PC computer data acquisition system. The other catheter was used for drug injections. The functionality of the sympathetic and parasympathetic branches of the autonomic nervous system were independently evaluated by intravascular injections of the vasoconstricting $\alpha-1$ adrenergic receptor agonist phenylephrine (5 and $25 \mu \mathrm{g})$ and the vasodilating nitric oxide donor sodium nitroprusside (5 and $15 \mu \mathrm{g})$. This was followed by autonomic nervous system blockers glycopyrrolate (a peripheral acting quaternary amine muscarinic receptor antagonist, $20 \mu \mathrm{g})$ and propranolol ( $\beta$-adrenergic receptor antagonist, $50 \mu \mathrm{g}$ ) and reinfusions of phenylephrine and sodium nitroprusside to confirm abolition of the baroreceptor reflex. All drug injections were administered intrarterially in a volume of $100 \mu \mathrm{l}$ of $0.9 \%$ aqueous saline heparinized at $7 \mathrm{U} / \mathrm{ml}$ and injected over $7 \mathrm{~s}$. HR was determined from the beat-to-beat systolic pressure peak intervals.

\section{DOBUTAMINE CHALLENGE}

We used dobutamine to probe the integrity of the cardiac $\beta-1$ adrenergic receptor as reflected in $\mathrm{HR}$ and rate of left ventricular pressure change during systole (inotropic response) and diastole (lusitropic response). Thyl-aSyn and WT mice were anesthetized with ketamine, xylazine, and buprenorphine and placed on a warming pad. HR and temperature were continuously monitored during surgery. Once anesthetized, the right carotid artery was catheterized and a 1.4 Fr catheter (Millar Instruments, Houston, TX, USA) was advanced into the left ventricle to obtain a dynamic pressure signal that was mathematically differentiated into in vivo indices of cardiac muscle inotropy $(+d P / d T)$ and lusitropy $(-d P / d T)(26)$. A femoral artery was also catheterized as above for injection of dobutamine, a $\beta$-1 adrenergic receptor agonist. Dobutamine was injected in serial doses of $3,6,15$, and $30 \mathrm{ng} / \mathrm{g}$ with at least a 5 -min recovery period between injections as an adrenergic post-synaptic receptor challenge test. Measurements were acquired with Hem Software (Notocord Systems V4.2,
Croissy sur Seine, France). HR and left ventricular pressure were recorded $150 \mathrm{~s}$ after injections and averaged over a 10-s period. Maximum and minimum $d P / d T$ were calculated during this $10-s$ period.

\section{TELEMETRIC ASSESSMENT}

Arterial pressure and cage activity was measured simultaneously in awake, freely moving Thyl-aSyn and WT mice using radio telemetry transducers (TA11PA-C10; Data Sciences International Inc., St. Paul, MN, USA). Transmitter units were implanted subcutaneously along the mouse's ventral side under the ketamine, xylazine, and buprenorphine anesthesia. The transmitter blood pressure catheter was fed over the shoulder and inserted into the left carotid artery under sterile surgical conditions (30). Data recording from the mice began immediately following implantation via an antenna receiver under the cage connected to a computer system. Pressure waveforms and activity data were collected, analyzed, and displayed with the telemetry software. For all studies, $20 \mathrm{~s}$ of data were collected every $10 \mathrm{~min}$ for the duration of the study. Data waveforms and parameters were analyzed with the DSI analysis program (ART 4.0) to determine differences in systolic, diastolic, and mean arterial pressures plus cage activity and HRs between Thyl-aSyn and WT mice during the entire light-dark diurnal cycle. Data for the hours surrounding the weekly scheduled cage changing were excluded from analysis. The data were averaged at the same time of day to create "foldagrams" to reveal any variances (dysfunction) and compare changes between groups under baseline conditions (30).

We tested tonic vagal release of acetylcholine at the muscarinic receptor of cardiac pacemaker cells with the muscarinic antagonist atropine $[1 \mathrm{mg} / \mathrm{kg}$, ip; (31)] administered to both Thy1-aSyn and WT mice. We documented blood pressure and baroreceptor reflex induced HR changes after phenylephrine [ $3 \mathrm{mg} / \mathrm{kg}$, ip; (32)] and sodium nitroprusside $[1 \mathrm{mg} / \mathrm{kg}$, sc; (33)]. Each drug was administered at the same time of day at least 2 days apart to allow for complete drug clearance from the ip injection. Saline was used as the vehicle and administered before each drug injection. Blood pressure and HR were recorded continuously in the home cage, following saline, and following drug administration.

\section{DATA EXPRESSION AND STATISTICS}

The hemodynamic experiment plots (Figures 1A-F) depict the baseline and acute post-drug pressure and HR data pairs as means and standard errors, computed as a function of condition, based on the nine mice in each experimental cell. The slope and $R^{2}$ statistics were derived with standard bivariate linear regression analyses, determined from the raw systolic and beats per minute data pairs, as a function of the genotype $\times$ drug conditions, but collapsed across the three doses of each drug (i.e., $n=27$ for each genotype $\times$ drug cell). These and the chronic telemetric data are also expressed as the ratio of the change in HR in BPM to the change in systolic blood pressure in $\mathrm{mmHg}$, or $\Delta \mathrm{HR} / \Delta \mathrm{SBP}$. For the dobutamine challenge test and cardiac contractility experiments data are expressed as left ventricular $+d P / d T_{\max }$ and $-d P / d T_{\text {min }}$. A mixed design ANOVA was used to compare genotypes and dose of drug in the hemodynamic and contractility experiments. Student's $t$-test or Mann-Whitney $U$ were applied 

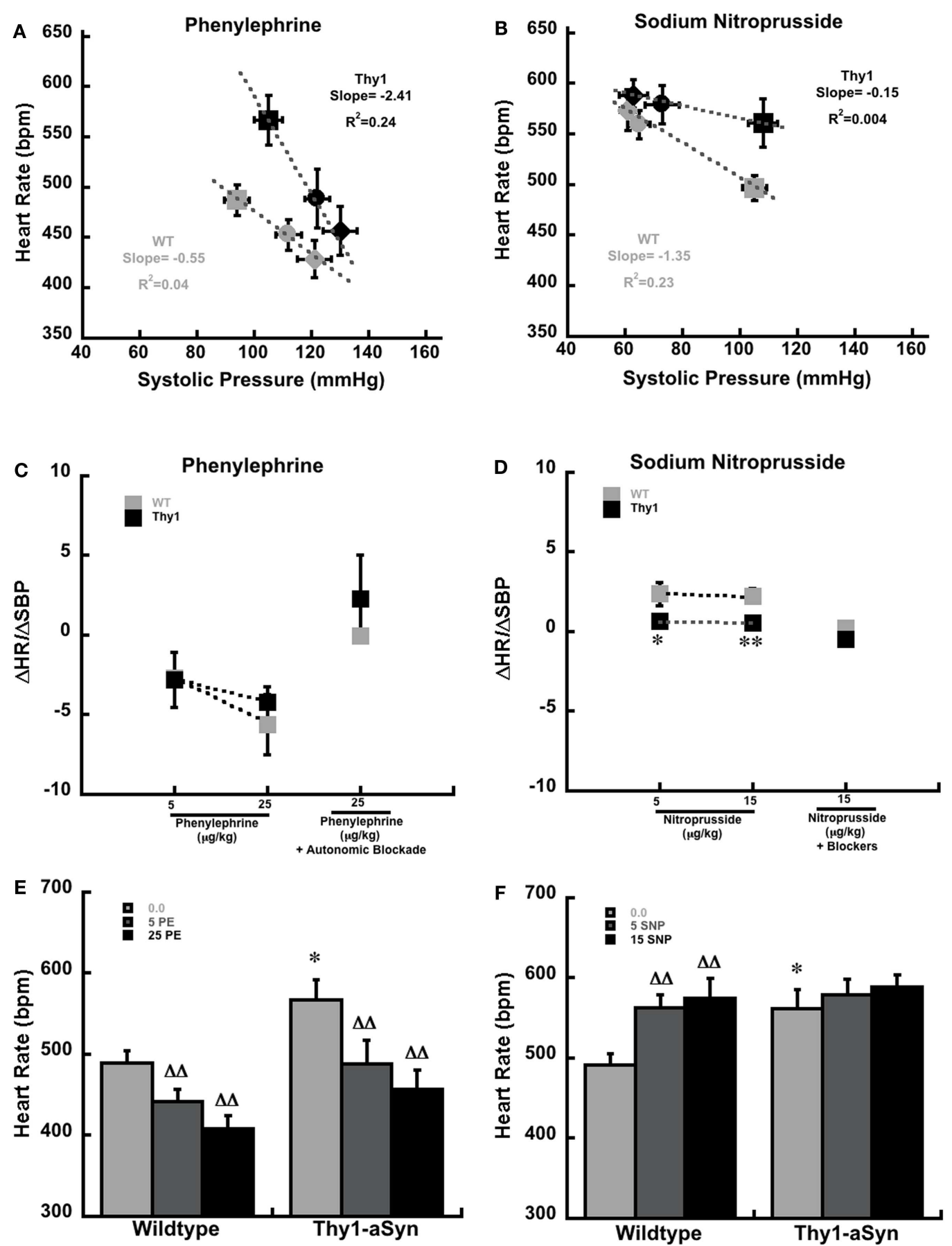

FIGURE 1 | Systolic pressure and heart rate at baseline (squares) and in response to phenylephrine $(A)$ and sodium nitroprusside $(B)$ in anesthetized WT (gray; $n=9$ ) Thy1-aSyn (Black; $n=9$ ) mice at

9-12 months of age. Mice received $5 \mu \mathrm{g}$ (circles) and $25 \mu \mathrm{g}$ (diamonds) of intravenous phenylephrine and $5 \mu \mathrm{g}$ (circles) and $15 \mu \mathrm{g}$ (diamonds) of intravenous sodium nitroprusside. The slope and $R^{2}$ values were derived from four separate regression equations, based on all available pairs of systolic blood pressure $(\mathrm{mm} / \mathrm{Hg}$ ) and heart rate (beats per minute) scores for each condition and drug, rather than the condition means and standard errors that are depicted in the plot. The baroreceptor sensitivity index $(\Delta \mathrm{HR} / \Delta \mathrm{SBP})$ following serial doses of phenylephrine alone and phenylephrine $(25 \mu \mathrm{g} / \mathrm{kg})$

following autonomic blockade with glycopyrrolate and propanolol (C). $\Delta \mathrm{HR} / \Delta \mathrm{SBP}$ following serial doses of sodium nitroprusside alone and sodium nitroprusside $(15 \mu \mathrm{g} / \mathrm{kg})$ following autonomic blockade with glycopyrrolate and propanolol (D). ${ }^{*},{ }^{*}$ Represents $p<0.05,0.01$, respectively compared to WT at the same dose. Heart rate measurements at baseline $(0.0 \mu \mathrm{g} / \mathrm{kg})$ and following serial doses of phenylephrine [5 and $25 \mu \mathrm{g} / \mathrm{kg}$; (E)]. Heart rate measurements at baseline $(0.0 \mu \mathrm{g} / \mathrm{kg})$ and following serial doses of sodium nitroprusside [5 and $15 \mu \mathrm{g} / \mathrm{kg}$; (F)]. * Represents $p<0.01$ compared to WT at same dose, DD represents $p<0.01$ compared to baseline $(0.0)$ within same genotype (Student's $t$-test and mixed design ANOVA followed by Fisher's LSD). 
to analyze morphometry parameters and arterial telemetry data between Thyl-aSyn and WT mice. Fisher's Least Significant Difference was used for post hoc analyses. All statistics were calculated with GB-Stat software (Dynamic Microsystems, Inc., Silver Spring, MD, USA, 2000). The level of significance was set at $p<0.05$.

\section{RESULTS}

\section{MORPHOMETRY PARAMETERS}

Morphometry measures included measurements of body, heart, liver, and lung weights, and tibia length in Thyl-aSyn and WT mice (Table 1). Comparisons between WT and Thyl-aSyn mice using Student's $t$-test showed that Thyl-aSyn mice weighed significantly less than WT mice, a difference we reported previously in this mutant line (19). While there were no significant differences in any of the other measures, heart and liver weights tended to be smaller in Thyl-aSyn mice but the difference did not reach significance ( $p=0.08$ and $p=0.06$, respectively).

\section{BASELINE HEART RATE AND SYSTOLIC BLOOD PRESSURE}

Baseline systolic blood pressure measurements did not differ between conscious or anesthetized WT and Thyl-aSyn mice $(p>0.05)$. However, baseline HR measures were significantly different between genotypes under anesthesia during the acute hemodynamic studies (Table 2); Thy1-aSyn mice had a higher HR compared to WT mice $(p<0.05)$. In contrast, conscious WT and Thyl-aSyn mice equipped with arterial telemetry had comparable baseline HRs during both the light and dark cycles (Table 2).

\section{HEMODYNAMIC ASSESSMENT}

The baroreflex response to the injection of phenylephrine and sodium nitroprusside in anesthetized Thy1-aSyn and WT mice are plotted in Figures 1A,B. Though the plots show averaged pressure and heart values for each condition for clarity, the individual baseline systolic pressures were measured over a wide range of values from 48 to $159 \mathrm{mmHg}$ in WT mice and from 41 to $157 \mathrm{mmHg}$ in Thy1-aSyn mice. Linear regression analysis from the raw data pairs ( $n=27$ pairs per study) are drawn through the averaged data points under each condition in Figures 1A,B. These data are also plotted as the $\Delta H R / \Delta S B P$ score (baroreflex sensitivity index) in Figures 1C,D. These data clearly show that phenylephrine produced a similar increase in systolic blood pressure and reflex decrease in HR in WT and Thyl-aSyn mice resulting in $\Delta \mathrm{HR} / \triangle \mathrm{SBP}$ scores that did not differ between genotypes over this range of baseline pressures (Figure 1C). As expected with combined $\beta$-adrenergic and muscarinic receptor blockade, the $\Delta \mathrm{HR} / \Delta \mathrm{SBP}$ response to phenylephrine following $\beta$-adrenergic and muscarinic blockade also did not differ between genotypes (Figure 1C). In contrast, the response to sodium nitroprusside in WT mice showed the characteristic decrease in systolic blood pressure and increased HR, while in Thyl-aSyn mice systolic blood pressure decreased but HR remained close to their initial baseline values regardless of dose (Figures 1B,D). Here, Thyl-aSyn regression slope was very shallow and $\Delta \mathrm{HR} / \Delta \mathrm{SBP}$ scores were significantly lower compared to WT mice $(p<0.05)$. The $\Delta \mathrm{HR} / \triangle \mathrm{SBP}$ response to sodium nitroprusside following $\beta$-adrenergic and muscarinic blockade did not differ between genotypes (Figure 1D).
Table 1 | Morphometry parameters in Thy1-aSyn and wildtype mice at 9-12 months of age.

\begin{tabular}{lcc}
\hline & Wildtype & Thy1-aSyn \\
\hline Body weight $(\mathrm{g})$ & $42.12 \pm 2.60$ & $31.99 \pm 2.36^{*}$ \\
Heart weight $(\mathrm{mg})$ & $203.43 \pm 13.42$ & $172.93 \pm 9.75$ \\
Lung weight $(\mathrm{mg})$ & $203.98 \pm 8.35$ & $208.92 \pm 27.94$ \\
Liver weight $(\mathrm{g})$ & $1.45 \pm 0.17$ & $1.02 \pm 0.12$ \\
Tibia length $(\mathrm{mm})$ & $18.10 \pm 0.21$ & $18.02 \pm 0.15$ \\
Heart weight/body weight & $4.86 \pm 0.23$ & $5.50 \pm 0.24$ \\
Heart weight/tibia length & $11.24 \pm 0.74$ & $9.59 \pm 0.52$ \\
\hline
\end{tabular}

${ }^{*} p<0.05$ compared to wildtype.

Table 2 | Baseline heart rate and blood pressure (BP) in anesthetized and awake Thy1-aSyn and wildtype mice.

\begin{tabular}{lllllc}
\hline Genotype & $\begin{array}{l}\text { Age } \\
\text { (m) }\end{array}$ & & Cycle & $\begin{array}{l}\text { Heart rate } \\
\text { (beats/min) }\end{array}$ & $\begin{array}{l}\text { Systolic BP } \\
\text { (mmHg) }\end{array}$ \\
\hline Wildtype & $9-12$ & Anesthetized & Light & $489 \pm 14$ & $97 \pm 4$ \\
Thy1-aSyn & $9-12$ & Anesthetized & Light & $567 \pm 25^{*}$ & $106 \pm 5$ \\
Wildtype & $3-5$ & Awake & Light & $475 \pm 7$ & $108 \pm 3$ \\
Thy1-aSyn & $3-5$ & Awake & Light & $498 \pm 24$ & $111 \pm 3$ \\
Wildtype & $3-5$ & Awake & Dark & $544 \pm 13$ & $127 \pm 1$ \\
Thy1-aSyn & $3-5$ & Awake & Dark & $589 \pm 27$ & $129 \pm 3$ \\
\hline
\end{tabular}

${ }^{*} p<0.05$ compared to wildtype.

Analysis of HR in WT and Thy1-aSyn mice showed phenylephrine caused similar HR decreases in both genotypes following administration of phenylephrine [Figure 1E; $F(1,16)=4.33$, $p>0.05$ for genotype and $F(2,32)=39.47, p<0.01$ for drug dose]. However, analysis of HR following sodium nitroprusside revealed that WT but not Thy1-aSyn showed significant increases in HR after each dose [Figure 1F; $F(1,16)=1.69, p>0.05$ for genotype and $F(2,32)=25.65, p<0.01$ for drug dose, and $F(2,32)=7.34, p<0.05$ for genotype $\times$ drug dose interaction].

\section{DOBUTAMINE CHALLENGE}

Left ventricular inotropy (contraction) and lusitropy (relaxation) $( \pm d P / d T)$ were measured in WT and Thyl-aSyn mice at 912 months of age (Figure 2). Serial infusions of the $\beta$-adrenergic agonist dobutamine resulted in similar left ventricular contractility $(+d P / d T$; Figure $2 \mathbf{A})$ and relaxation $(-d P / d T$; Figure $2 \mathbf{B})$ between WT and Thyl-aSyn mice $(p>0.05)$. HR responses were also similar between genotypes $(p>0.05$; Figure $2 \mathrm{C})$.

\section{TELEMETRIC ASSESSMENT}

Because Thyl-aSyn mice had a higher HR at baseline under anesthesia we wanted to determine if the differences we observed were due to an abnormal response to the anesthesia or to impaired baroreflex. Therefore, a separate cohort of Thyl-aSyn and WT mice were implanted with arterial telemetry transducers. Due to poor post surgery survival at the 9- to 12-month age in Thy1aSyn mice the separate cohort of mice for telemetry was younger in age, 3-5 months. Similar to the hemodynamic experiment 

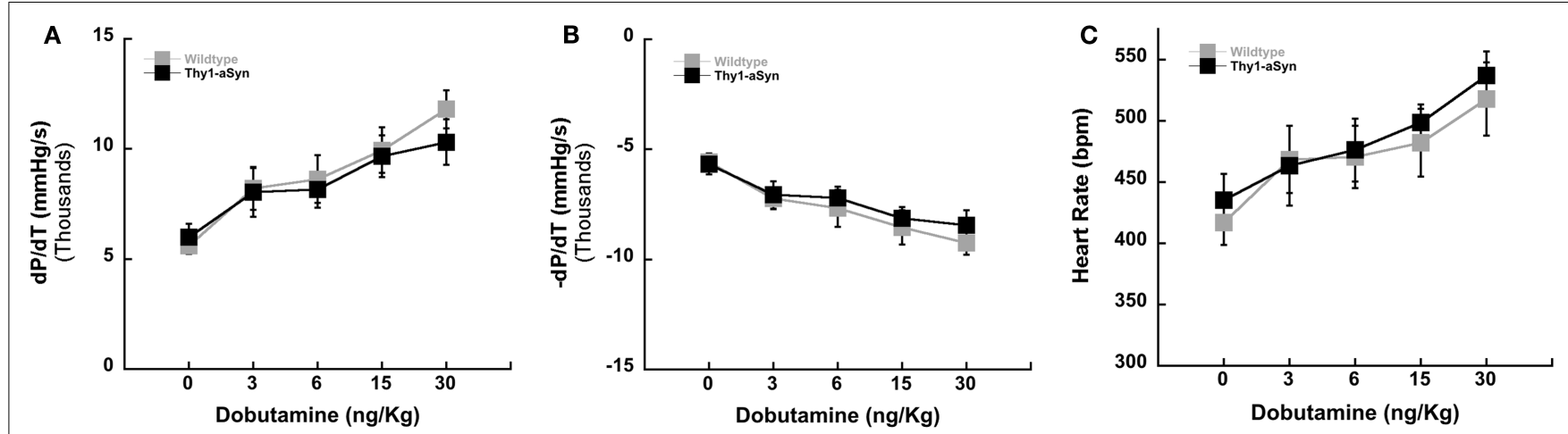

FIGURE 2 | Left ventricular contractility in WT $(\boldsymbol{n}=\mathbf{7})$ and Thy1-aSyn $(\boldsymbol{n}=\mathbf{7})$ at 9-12 months of age. Left ventricular positive $d P / d T$ [contractility; (A)], left ventricular negative $d P / d T$ [relaxation; (B)], and heart rate following administration of the $\beta$-adrenergic agonist dobutamine [(C); mixed design ANOVA].

under anesthesia, conscious mice were challenged pharmacologically with intraperitoneal phenylephrine and nitroprusside (ip). In addition the response to muscarinic blockade was measured using atropine. At 3-5 months of age baseline HR and systolic blood pressure did not differ between WT and Thy1-aSyn mice. Similar to the anesthetized experiment WT and Thy1-aSyn mice displayed comparable responses to phenylephrine and nitroprusside over a similar range of systolic pressures. There was no difference between the genotypes in $\Delta \mathrm{HR} / \Delta \mathrm{SBP}$ or HR scores following phenylephrine injections $(p>0.05$; Figures 3A,D). However, in response to sodium nitroprusside Thyl-aSyn mice once again showed a blunted HR response while WT showed characteristic tachycardia. Thyl-aSyn $\Delta \mathrm{HR} / \Delta \mathrm{SBP}$ scores were significantly decreased compared to WT $(p<0.05$; Figure 3B). Analysis of HR alone showed that HR significantly increased in WT but not in Thyl-aSyn mice following nitroprusside ( $p<0.05$; Figure $3 \mathrm{E})$. In response to muscarinic blockade $\Delta \mathrm{HR} / \Delta \mathrm{SBP}$ scores did not significantly differ between genotypes however, analysis of $\mathrm{HR}$ alone showed that $\mathrm{HR}$ significantly increased in WT but not in Thyl-aSyn mice following atropine (Figures 3C,F). The activity response did not significantly differ between genotypes in any of the drug conditions (Student's $t$-test, $p>0.05)$.

\section{DISCUSSION}

Baroreflex failure has been reported in both sporadic and alphasynuclein associated familial forms of PD $(4,15)$. While cardiovascular autonomic dysfunction is well established in PD, little is known about the underlying cause of the dysfunction. Until recently, there has been a lack of basic research on the nonmotor impairments associated with, and often present very early in humans with PD. However, with the potential early occurrence of many of the non-motor symptoms, a keen interest in these symptoms as possible early disease biomarkers has developed. For example, impaired HR variability observed in REM sleep behavior disorder may be an early indicator of PD (7). In the present study we show that overexpression of human alpha-synuclein in mice leads to impaired baroreflex control of HR prior to changes in striatal dopamine content and reminiscent of the baroreflex dysfunction observed in PD $(1,2)$. These findings are important because they provide a foundation for future studies aimed at identifying brain structures and pathological mechanisms associated with cardiovascular autonomic dysfunction in PD. In addition, these results underscore the usefulness of Thyl-aSyn mice in the study of early non-motor symptoms associated with PD.

Overall, with the exception of body weight, morphometry measures did not statistically differ between genotypes. We have previously reported decreased body weight in Thyl-aSyn compared to WT mice at 12 months of age without differences in overall food intake (19). We did however note a trend for heart and liver weights to be decreased in Thyl-aSyn mice.

The most profound functional differences were observed in response to administration of the vasodilator sodium nitroprusside. Here, anesthetized WT mice displayed the characteristic tachycardic response to the sudden drop in blood pressure produced by sodium nitroprusside, over a wide range of initial baseline values. But the Thy1-aSyn mice showed no significant change in HR during an equivalent transient decrease in systolic blood pressure suggesting impairments in autonomic modulation of cardiac function in Thyl-aSyn mice at an early age, before reductions in striatal dopamine content are observed (23). During these experiments it was noted that Thy1-aSyn mice appeared more sensitive than WT to the anesthetic combination of ketamine, xylazine, and buprenorphine. This is consistent with a recent study in the same Thyl-aSyn mouse line where the authors report increased sensitivity to the common rodent anesthetic xylazine (22). Due to this increased sensitivity it is possible that the HR differences observed in the Thyl-aSyn mice could be due in part to the anesthesia and not impaired baroreflex function. Therefore, we performed an additional set of experiments where WT and Thy1aSyn mice were equipped with arterial telemetric transducers to allow HR and SBP measurements in conscious/awake mice. In this experiment we found that baseline HR and SBP were not different between genotypes suggesting the difference seen in anesthetized mice may have been a consequence of abnormal response to the anesthesia, or only develop at a later age. However, HR and SBP responses to phenylephrine and sodium nitroprusside were similar to what we observed in the previous experiments under anesthesia. In Thyl-aSyn mice sodium nitroprusside administration resulted in a significant decrease in SBP and a blunted HR response. Typically, during a drop in blood pressure efferent sympathetic outflow 

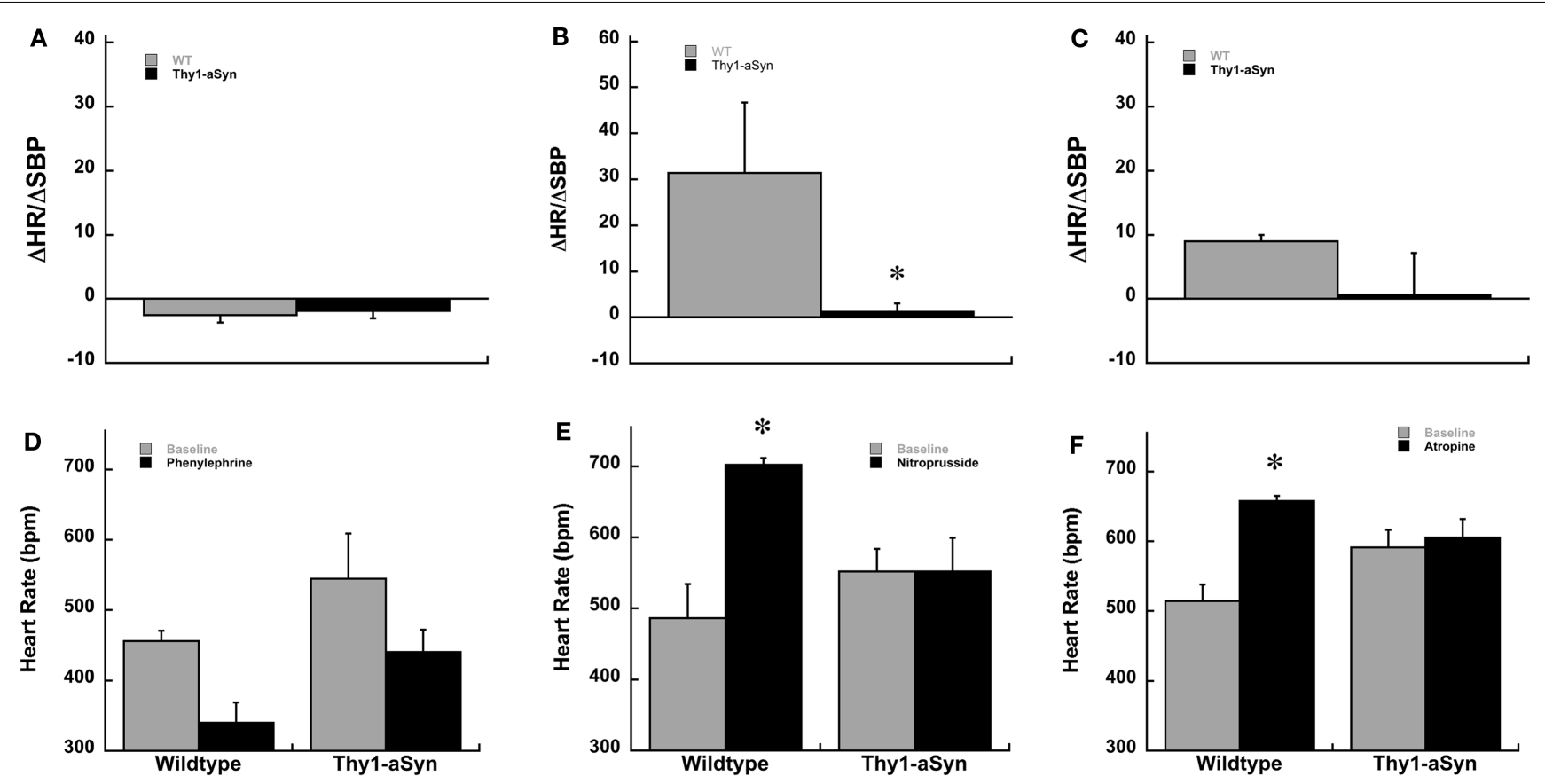

FIGURE 3 | Baroreceptor sensitivity, $\Delta \mathrm{HR} / \Delta \mathrm{SBP}$, in awake Thy1-aSyn $(n=3-5)$ and WT $(n=3-4)$ mice at 3-5 months following systemic administration of phenylephrine (A), sodium nitroprusside (B), and atropine (C). Heart rate responses following systemic phenylephrine (D), sodium nitroprusside (E), and atropine (F). ${ }^{*}$ Represents $p<0.05$ compared to WT, $\Delta$ represents $p<0.05$ compared to baseline $(0.0 \mathrm{mg} / \mathrm{kg})$ within same genotype (Mann-Whitney $U$ and mixed design ANOVA followed by Fisher's LSD). is increased $(34,35)$. Thus, in the present study the blunted HR response to sodium nitroprusside suggests the sympathetic component of the baroreflex is impaired in Thyl-aSyn mice over a wide range of ages. In PD patients with or without orthostatic hypotension, a similar blunted HR increase has been reported in response to the feet down tilt maneuver and in the Valsalva maneuver $(5,36$, 37). It has been proposed that the combination of baroreflex failure and widespread noradrenergic denervation contributes to the development of orthostatic and post-prandial hypotension and supine hypertension commonly seen in PD (38).

Adrenergic supersensitivity in response to sympathetic denervation has been reported in patients with PD (39). Therefore, similar to Nakamura et al. (39) we tested left ventricular contractility of the heart in response to administration of the $\beta$-adrenergic agonist dobutamine in WT and Thyl-aSyn mice. There were no significant differences in inotropy or lusitropy between WT and Thyl-aSyn mice indicating no evidence of receptor supersensitivity. This is consistent with a recent finding showing no differences in contractility in patients in the early stages of PD (40).

Acetylcholine released from parasympathetic nerves reduces HR by binding primarily to M2 subtype muscarinic receptors on sinoatrial nodal cells in the heart. Blockade of M2 muscarinic receptors results in an increase in $\mathrm{HR}$ (31). In the present study WT but not Thyl-aSyn mice showed a significant increase in $\mathrm{HR}$ in response to the systemic muscarinic antagonist atropine. In addition, although not statistically significant $(p=0.08)$, WT mice showed a mean increase in HR in response to glycopyrrolate while Thy1-aSyn mice showed on average a decrease in HR in response to the peripheral muscarinic antagonist. The abnormal response to atropine in Thyl-aSyn mice is similar to a recent study measuring HR variability parameters in mice that express A53T mutant human alpha-synuclein under the Thyl promoter. Here, the authors show increased baseline HR and reduced change in HR in response to systemic atropine in A53T compared to WT mice suggesting parasympathetic dysfunction in the mutant mice (11). However in contrast, mice with A53T or A30P mutations in alphasynuclein generated using PAC transgenesis showed no alterations in $\mathrm{HR}$ variability parameters at 12 months of age, perhaps due to the low level of expression of the transgenic protein (10). The abnormal cardiovascular response to atropine taken together with the impaired HR response to sodium nitroprusside and previous work showing gastrointestinal dysfunction in Thyl-aSyn mice suggest impairment of both sympathetic and parasympathetic systems in Thy1-aSyn mice $(19,20)$. Thus, the Thy1-aSyn mice show a potentially broader range of autonomic anomalies than previously reported in other mouse models of synucleinopathy $(10,11)$.

The pathological mechanisms underlying cardiovascular autonomic dysfunction in PD remain unclear. In PD sympathetic denervation is observed in patients with and without orthostatic hypotension and has been reported to develop before and after the diagnosis of $\operatorname{PD}(4,38,41)$. In addition to sympathetic denervation alpha-synuclein containing Lewy bodies can be observed in cardiac and brain regions important for sympathetic regulation of blood pressure and $\mathrm{HR}$ in humans suggesting that alpha-synuclein pathology may contribute to cardiovascular autonomic anomalies commonly observed in PD (12-14). In the brain 
of Thy1-aSyn mice human alpha-synuclein mRNA expression is high throughout the brainstem and proteinase K-resistant alphasynuclein inclusions develop in the locus coeruleus and substantia nigra $(16,17)$. In a recent study in the same line of Thyl-aSyn mice human alpha-synuclein protein was observed in the ventricular and atrial walls of the heart localized within noradrenergic fibers (22). Thus, it is unclear at this point whether the functional impairments are associated with either peripheral or central pathology or a combination of both. Functional deficits in central noradrenergic and dopaminergic systems have been observed in this mouse line (23, 24, 42, Maidment and Chesselet, unpublished observations) and dysregulation of central noradrenergic and dopaminergic systems has been shown to alter baroreceptor function in rodents suggesting central catecholamine system dysfunction could be a contributing factor $(8,27)$. Sodium nitroprusside, in addition to its peripheral vasodilator actions, is also known to activate central noradrenergic neurons in the locus coeruleus (43). Interestingly, the most profound impairment in Thyl-aSyn mice was a lack of nitroprusside-induced tachycardia, which was shown in both anesthetized and awake conditions. However, further research is needed to determine the exact contribution of peripheral and central noradrenergic and dopaminergic dysfunction in the autonomic regulation of blood pressure and HR in Thyl-aSyn mice.

\section{REFERENCES}

1. Szili-Török T, Kálmán J, Paprika D, Dibó G, Rózsa Z, Rudas L. Depressed baroreflex sensitivity in patients with Alzheimer's and Parkinson's disease. Neurobiol Aging (2001) 22:435-8. doi:10. 1016/S0197-4580(01)00210-X

2. Goldstein DS. Dysautonomia in Parkinson's disease: neurocardiological abnormalities. Lancet $\mathrm{Neu}$ rol (2003) 2:669-76. doi:10.1016/ S1474-4422(03)00555-6

3. Kaufmann $H$, Nahm K, Purohit D, Wolfe D. Autonomic failure as the initial presentation of Parkinson disease and dementia with Lewy bodies. Neurology (2004) 63:1093-5. doi:10.1212/01. WNL.0000138500.73671.DC

4. Goldstein DS. Orthostatic hypotension as an early finding in Parkinson's disease. Clin Auton Res (2006) 16:46-54. doi:10.1007/s10286-0060317-8

5. Barbic F, Perego F, Canesi M, Gianni M, Biagiotti S, Costantino G, et al. Early abnormalities of vascular and cardiac autonomic control in Parkinson's disease without orthostatic hypotension. Hypertension (2007) 49:120-6. doi:10.1161/ 01.HYP.0000250939.71343.7c

6. Goldstein DS, Sharabi Y, Karp BI, Bentho O, Saleem A, Pacak K, et al. Cardiac sympathetic denervation preceding motor signs in Parkinson disease. Cleve Clin J Med (2009)
76(Suppl 2):S47-50. doi:10.3949/ ccjm.76.s2.10

7. Valappil RA, Black JE, Broderick MJ, Carrillo O, Frenette E, Sullivan SS, et al. Exploring the electrocardiogram as a potential tool to screen for premotor Parkinson's disease. Mov Disord (2010) 25(14):2296-303. doi: $10.1002 / \mathrm{mds} .23348$

8. Lu SF, Young HJ, Lin MT. Nigrostriatal dopamine system mediates baroreflex sensitivity in rats. $\mathrm{Neu}$ rosci Lett (1995) 190:17-20. doi: 10.1016/0304-3940(95)11489-J

9. Takatsu H, Nishida H, Matsuo H, Watanabe S, Nagashima K, Wada H, et al. Cardiac sympathetic denervation from the early stage of Parkinson's disease: clinical and experimental studies with radiolabeled MIBG. J Nucl Med (2000) 41:71-7.

10. Kuo YM, Li Z, Jiao Y, Gaborit N, Pani AK, Orrison BM, et al. Extensive enteric nervous system abnormalities in mice transgenic for artificial chromosomes containing Parkinson diseaseassociated alpha-synuclein gene mutations precede central nervous system changes. Hum Mol Genet (2010) 19(9):1633-50. doi: $10.1093 / \mathrm{hmg} / \mathrm{ddq} 038$

11. Griffioen KJ, Rothman SM, Ladenheim B, Wan R, Vranis $\mathrm{N}$, Hutchison E, et al. Dietary energy intake modifies brainstem autonomic dysfunction caused by mutant $\alpha$-synuclein. Neurobiol

\section{CONCLUSION}

The present study shows that Thyl-aSyn mice, a model of synucleinopathy, have impaired baroreflex control of HR analogous to what is observed in patients with the synucleinopathy PD $(5,36,37)$. Furthermore, the cardiovascular autonomic dysfunction detected in the Thyl-aSyn mice occurs prior to dopaminergic alterations in the striatum. Similarly in PD cardiovascular autonomic dysfunction is also reported to occur early, before the onset of overt motor symptoms. While the mechanisms contributing to cardiovascular anomalies in PD remain to be established the Thy1-aSyn mice provide a novel genetic model in which to study the contribution of alpha-synuclein pathology to autonomic dysfunction in PD.

\section{ACKNOWLEDGMENTS}

Supported by PHS grant P50NS38367 UCLA Morris K. Udall Parkinson's Disease Research Center of Excellence (MarieFrançoise Chesselet), American Parkinson Disease Association Center of Excellence at UCLA (Marie-Françoise Chesselet), the Gardner Family Center for Parkinson's Disease and Movement Disorders (Sheila M. Fleming), and the Parkinson's Disease Foundation (Sheila M. Fleming).

Aging (2013) 34:928-35. doi:10. 1016/j.neurobiolaging.2012.07.008

12. Forno LS, Norville RL. Ultrastructure of Lewy bodies in the stellate ganglion. Acta Neuropathol (1976) 34:183-97. doi: 10.1007/BF00688674

13. Iwanaga K, Wakabayashi K, Yoshimoto M, Tomita I, Satoh $\mathrm{H}$ Takashima $\mathrm{H}$, et al. Lewy bodytype degeneration in cardiac plexus in Parkinson's and incidental Lewy body diseases. Neurology (1999) 52:1269-71. doi:10.1212/WNL.52. 6.1269

14. Braak H, Del Tredici K, Rub U, de Vos RA, Jansen Steur EN, Braak E. Staging of brain pathology related to sporadic Parkinson's disease. Neurobiol Aging (2003) 24:197-211. doi: 10.1016/S0197-4580(02)00065-9

15. Singleton A, Gwinn-Hardy K, Sharabi Y, Li ST, Holmes C, Dendi R, et al. Association between cardiac denervation and parkinsonism caused by alpha-synuclein gene triplication. Brain (2004) 127:768-72. doi: 10.1093/brain/awh081

16. Rockenstein E, Mallory M, Hashimoto M, Song D, Shults CW, Lang I, et al. Differential neuropathological alterations in transgenic mice expressing alphasynuclein from the platelet-derived growth factor and Thy-1 promoters. J Neurosci Res (2002) 68:568-78. doi:10.1002/jnr.1023
17. Fernagut PO, Hutson CB, Fleming SM, Tetreaut NA, Salcedo J, Masliah E, et al. Behavioral and histopathological consequences of paraquat intoxication in mice: effects of alpha-synuclein over-expression. Synapse (2007) 61:991-1001. doi: 10.1002/syn.20456

18. Fleming SM, Tetreault NA, Mulligan $\mathrm{CK}$, Hutson CB, Masliah E, Chesselet MF. Olfactory dysfunction in mice overexpressing human wildtype alpha-synuclein. Eur Neurosci (2008) 28:247-56. doi:10. 1111/j.1460-9568.2008.06346.x

19. Wang L, Fleming SM, Chesselet M-F, Taché Y. Abnormal colonic motility in mice overexpressing human wildtype alpha-synuclein. Neuroreport (2008) 19:873-6. doi: 10.1097/WNR.0b013e3282ffda5e

20. Wang L, Magen I, Yuan PQ, Subramaniam SR, Richter F, Chesselet MF, et al. Mice overexpressing wild-type human alphasynuclein display alterations in colonic myenteric ganglia and defecation. Neurogastroenterol Motil (2012) 24(9):e425-36. doi:10.1111/ j.1365-2982.2012.01974.x

21. Magen I, Fleming SM, Zhu C, Garcia EC, Cardiff KM, Dinh D, et al. Cognitive deficits in a mouse model of pre-manifest Parkinson's disease. Eur J Neurosci (2012) 35(6):870-82. doi:10.1111/j.14609568.2012.08012.x 
22. Hallett PJ, McLean JR, Kartunen A, Langston JW, Isacson O. Alphasynuclein overexpressing transgenic mice show internal organ pathology and autonomic deficits. Neurobiol Dis (2012) 47(2):258-67. doi: 10.1016/j.nbd.2012.04.009

23. Lam HA, Wu N, Cely I, Kelly RL, Hean S, Richter F, et al. Elevated tonic extracellular dopamine concentration and altered dopamine modulation of synaptic activity precede dopamine loss in the striatum of mice overexpressing human $\alpha$-synuclein. J Neurosci Res (2011) 89:1091-102. doi:10.1002/jnr.22611

24. Fleming SM, Salcedo J, Hutson CB, Rockenstein E, Masliah E, Levine MS, et al. Behavioral effects of dopaminergic agonists in transgenic mice overexpressing human wildtype $\alpha$-synuclein. Neuroscience (2006) 142:1245-53. doi:10.1016/j. neuroscience.2006.07.005

25. Fleming SM, Mulligan CK, Richter F, Mortazavi F, Lemesre V, Frias C, et al. A pilot trial of the microtubuleinteracting peptide (NAP) in mice overexpressing alpha-synuclein shows improvement in motor function and reduction of alphasynuclein inclusions. Mol Cell Neurosci (2011) 46(3):597-606. doi:10.1016/j.mcn.2010.12.011

26. Shai SY, Harpf AE, Babbitt CJ, Jordan MC, Fishbein MC, Chen J, et al. Cardiac myocyte-specific excision of the betal integrin gene results in myocardial fibrosis and cardiac failure. Circ Res (2002) 90:458-64. doi: 10.1161/hh0402.105790

27. Holschneider DP, Scremin OU, Roos KP, Chialvo DR, Chen K, Shih JC. Increased baroreceptor response in mice deficient in monoamine oxidase A and B. Am J Physiol Heart Circ Physiol (2002) 282:H964-72.
28. Jordan MC, Henderson SA, Han T, Fishbein MC, Philipson KD, Roos KP. Myocardial function with reduced expression of the sodiumcalcium exchanger. J Card Fail (2010) 16(9):786-96. doi:10.1016/j. cardfail.2010.03.012

29. Schroeder AM, Loh DH, Jordan MC, Roos KP, Colwell CS. Baroreceptor reflex dysfunction in the BACHD mouse model of Huntington's disease. PLoS Curr (2011) 3:RRN1266. doi:10.1371/currents. RRN1266

30. Jordan MC, Zheng Y, Ryazantsev S, Rozengurt N, Roos KP, Neufeld EF. Cardiac manifestations in the mouse model of mucopolysaccharidosis I. Mol Genet Metab (2005) 86:233-43. doi:10. 1016/j.ymgme.2005.05.003

31. Bissonnette JM, Knopp SJ, Maylie J, Thong T. Autonomic cardiovascular control in methyl-CpGbinding protein 2 (Mecp2) deficient mice. Auton Neurosci (2007) 136(12):82-9. doi:10.1016/j.autneu.2007. 04.007

32. Gehrmann J, Hammer PE, Maguire CT, Wakimoto H, Triedman JK, Berul CI. Phenotypic screening for heart rate variability in the mouse. Am J Physiol Heart Circ Physiol (2000) 279(2):H733-40.

33. Kakiya S, Arima H, Yokoi H, Murase T, Yambe Y, Oiso Y. Effects of acute hypotensive stimuli on arginine vasopressin gene transcription in the rat hypothalamus. Am J Physiol Endocrinol Metab (2000) 279(4):E886-92.

34. Parati G, Di Rienzo M, Mancia G. Dynamic modulation of baroreflex sensitivity in health and disease. Ann N Y Acad Sci (2001) 940:469 87. doi:10.1111/j.1749-6632.2001. tb03699.x
35. Monahan KD. Effect of aging on baroreflex function in humans. Am J Physiol Regul Integr Comp Physiol (2007) 293(1):R3-12. doi:10.1152/ ajpregu.00031.2007

36. Goldstein DS, Eldadah BA, Holmes C, Pechnik S, Moak J, Saleem A, et al. Neurocirculatory abnormalities in Parkinson disease with orthostatic hypotension: independence from levodopa treatment. Hypertension (2005) 46(6):1333-9. doi:10.1161/01.HYP.0000188052. 69549.e4

37. Idiaquez J, Benarroch EE, Rosales H, Milla P, Ríos L. Autonomic and cognitive dysfunction in Parkinson's disease. Clin Auton Res (2007) 17:93-8. doi:10.1007/s10286-0070410-7

38. Jain S, Goldstein DS. Cardiovascular dysautonomia in Parkinson disease: from pathophysiology to pathogenesis. Neurobiol Dis (2012) 46(3):572-80. doi:10.1016/j. nbd.2011.10.025

39. Nakamura T, Hirayama $M$, Ito $\mathrm{H}$, Takamori $\mathrm{M}$, Hamada $\mathrm{K}$ Takeuchi S, et al. Dobutamine stress test unmasks cardiac sympathetic denervation in Parkinson's disease. J Neuro Sci (2007) 263(1-2):133-8. doi: 10.1016/j.jns.2007.07.005

40. Buob A, Winter $\mathrm{H}$, Kindermann M, Becker G, Möller JC, Oertel WH, et al. Parasympathetic but not sympathetic cardiac dysfunction at early stages of Parkinson's disease. Clin Res Cardiol (2010) 99:701-6. doi: 10.1007/s00392-010-0170-6

41. Goldstein DS, Sharabi Y, Karp BI, Bentho O, Saleem A, Pacak K, et al. Cardiac sympathetic denervation preceding motor signs in Parkinson disease. Clin Auton Res (2007)
17(2):118-21. doi:10.1007/s10286007-0396- 1

42. Fleming SM, Jentsch JD, Chesselet M-F. Cognitive dysfunction in genetic mouse models of parkinsonism. In: Van Dam D, editor. Neuromethods: Animal Models of Dementia. New York, NY: SpringerHumana Press (2011). p. 485-92.

43. Curtis AL, Drolet G, Valentino RJ. Hemodynamic stress activates locus coeruleus neurons of unanesthetized rats. Brain Res Bull (1993) 31:737-44. doi: 10.1016/0361-9230(93)90150-A

Conflict of Interest Statement: The authors declare that the research was conducted in the absence of any commercial or financial relationships that could be construed as a potential conflict of interest.

Received: 20 March 2013; paper pending published: 09 April 2013; accepted: 09 July 2013; published online: 23 July 2013. Citation: Fleming SM, Jordan MC, Mulligan CK, Masliah E, Holden JG, Millard RW, Chesselet $M-F$ and Roos KP (2013) Impaired baroreflex function in mice overexpressing alphasynuclein. Front. Neurol. 4:103. doi: 10.3389/fneur.2013.00103

This article was submitted to Frontiers in Movement Disorders, a specialty of Frontiers in Neurology. Copyright (C) 2013 Fleming, Jordan, Mulligan, Masliah, Holden, Millard, Chesselet and Roos. This is an open-access article distributed under the terms of the Creative Commons Attribution License, which permits use, distribution and reproduction in other forums, provided the original authors and source are credited and subject to any copyright notices concerning any third-party graphics etc. 